\title{
PD43 - Body fat mass is positively associated with pediatric asthma
}

\author{
George V Guibas ${ }^{1 *}$, Yannis Manios², Paraskevi Xepapadaki ${ }^{1}$, George Moschonis², Nikolaos Douladiris', \\ Christina Mavrogianni ${ }^{2}$, Nikolaos G Papadopoulos ${ }^{1}$ \\ From 3rd Pediatric Allergy and Asthma Meeting (PAAM) \\ Athens, Greece. 17-19 October 2013
}

\section{Background}

Prevalence of pediatric overweight/obesity and pediatric asthma has been on the rise, with both conditions currently reaching epidemic proportions. Their concurrent rise alludes to potentially common characteristics of their pathophysiologic mechanisms; furthermore, excess fat mass may facilitate asthma induction via obesity-related inflammatory mediators, oxidant stress and mechanical chest restriction. However, although such a link is welldocumented in adults, it is not yet established in children. We thus opted to investigate into a potential adiposity/ asthma association in a cross-sectional, population-based study in preschoolers, by using several indices to assess fat mass.

\section{Methods}

Wheeze ever/in the last 12 months (current) and physician-diagnosed asthma were recorded from questionnaires filled in by the parents of 2015 children aged 9-13. Perinatal data was collected from their medical records and the questionnaires; anthropometric measurements and bioelectric impedance analysis (BIA) were conducted. Logistic regression models were build in the Statistical Package for Social Sciences (SPSS version 20.0), with the wheeze/asthma variables as main outcomes. A two-tailed $\mathrm{p}$ value less that 0.05 , was considered statistically significant.

\section{Results}

Physician-diagnosed asthma correlated with $\mathrm{z}$ scores of BMI (OR=1.17 95\%CI=1.05-1.31, $\mathrm{p}=0.005)$, waist circumference $(\mathrm{OR}=1.1695 \% \mathrm{CI}=1.03-1.32, \mathrm{p}=0.017)$, waistto-height ratio (OR=1.18 95\% CI=1.04-1.34, $\mathrm{p}=0.009)$, sum skinfold thickness at 4 sites (biceps, triceps, subscapular, suprailliac) $(\mathrm{OR}=1.2195 \% \mathrm{CI}=1.07-1.38, \mathrm{p}=0.002)$ and bioelectric impedance-derived percentage fat mass ( $\mathrm{OR}=1.23$ 95\% CI=1.07-1.40, $\mathrm{p}=0.003)$, following adjustment for several potential confounding factors (prenatal smoking, gestational age, birth weight, gender, parity, breastfeeding, passive smoking at home and parental educational level). Parental-reported current/ever wheeze was not associated with fat mass.

\section{Conclusions}

Body fat mass is positively linked to pediatric asthma prevalence in preadolescent children.

\section{Authors' details}

${ }^{1}$ Allergy Department, $2^{\text {nd }}$ Pediatric Clinic, University of Athens, Athens, Greece. '2Department of Nutrition and Dietetics, Harokopio University, Athens, Greece.

Published: 28 February 2014

\section{doi:10.1186/2045-7022-4-S1-P43}

Cite this article as: Guibas et al:: PD43 - Body fat mass is positively associated with pediatric asthma. Clinical and Translational Allergy 2014 4(Suppl 1):P43. 